
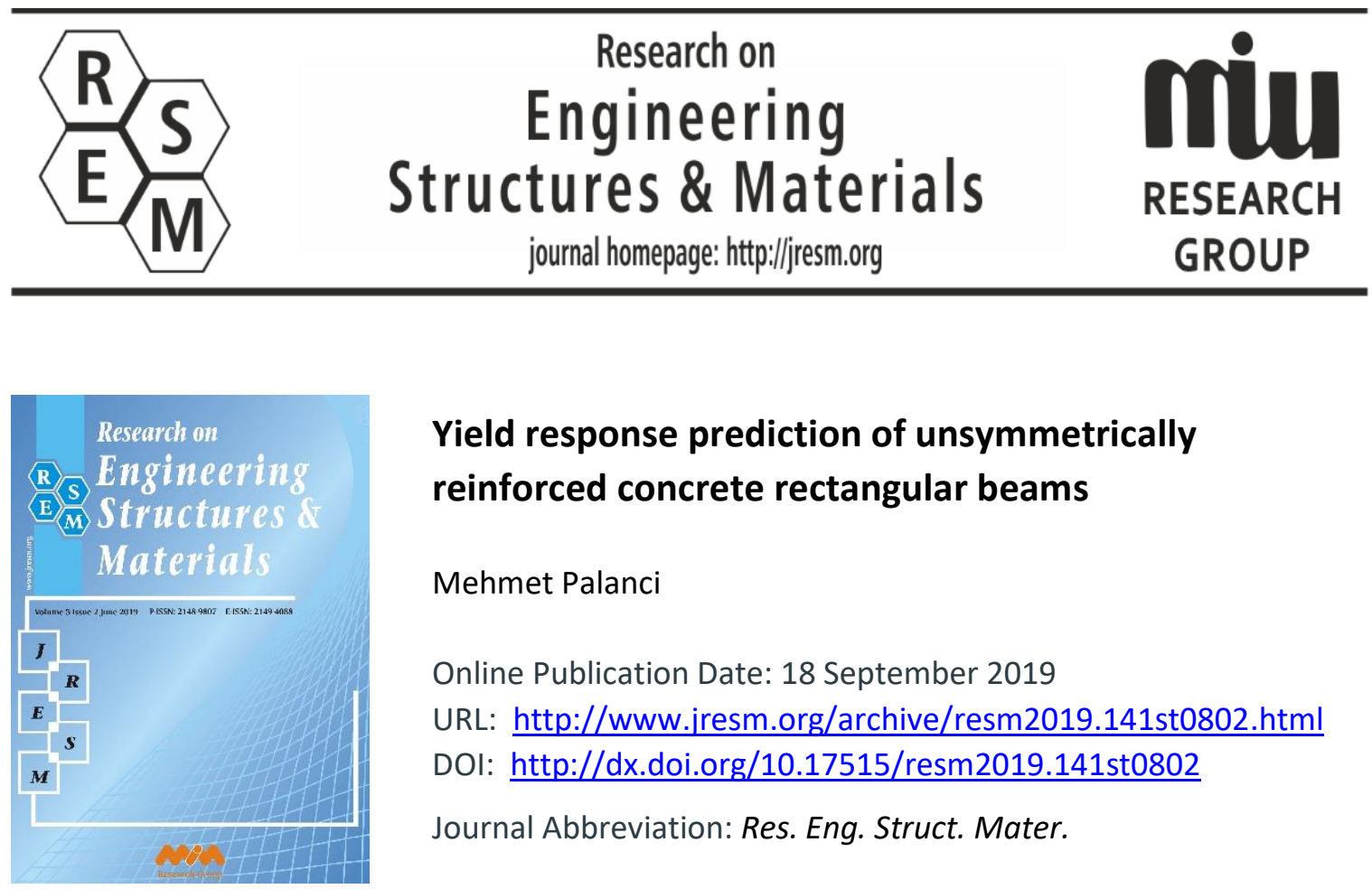

\title{
Yield response prediction of unsymmetrically reinforced concrete rectangular beams
}

\author{
Mehmet Palanci \\ Online Publication Date: 18 September 2019 \\ URL: http://www.jresm.org/archive/resm2019.141st0802.html \\ DOI: http://dx.doi.org/10.17515/resm2019.141st0802 \\ Journal Abbreviation: Res. Eng. Struct. Mater.
}

\section{To cite this article}

Palanci M. Yield response prediction of unsymmetrically reinforced concrete rectangular beams. Res. Eng. Struct. Mater., 2020; 6(2): 105-118.

\section{Disclaimer}

All the opinions and statements expressed in the papers are on the responsibility of author(s) and are not to be regarded as those of the journal of Research on Engineering Structures and Materials (RESM) organization or related parties. The publishers make no warranty, explicit or implied, or make any representation with respect to the contents of any article will be complete or accurate or up to date. The accuracy of any instructions, equations, or other information should be independently verified. The publisher and related parties shall not be liable for any loss, actions, claims, proceedings, demand or costs or damages whatsoever or howsoever caused arising directly or indirectly in connection with use of the information given in the journal or related means.

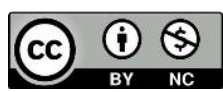

Published articles are freely available to users under the terms of Creative Commons Attribution - NonCommercial 4.0 International Public License, as currently displayed at here (the "CC BY - NC"). 


\title{
Research on Engineering Structures \& Materials
}

journal homepage: http://jresm.org

Research Article

\section{Yield response prediction of unsymmetrically reinforced concrete rectangular beams}

\author{
Mehmet Palanci* \\ Department of Civil Engineering, Istanbul Arel University, Istanbul, Turkey
}

\begin{tabular}{|c|c|}
\hline Article Info & Abstract \\
\hline $\begin{array}{l}\text { Article history: } \\
\text { Received } 02 \text { Aug } 2019 \\
\text { Revised } 11 \text { Sep } 2019 \\
\text { Accepted } 15 \text { Sep } 2019\end{array}$ & $\begin{array}{l}\text { Main components such as columns and beams of reinforced concrete (RC) } \\
\text { buildings are constructed as symmetrically and unsymmetrically reinforced. } \\
\text { Symmetrically reinforced concrete members are widely studied and some } \\
\text { analytical/numerical approaches are provided. However, unsymmetrically } \\
\text { reinforced concrete members are not adequately investigated and further }\end{array}$ \\
\hline $\begin{array}{l}\text { Reinforced Concrete } \\
\text { Structures; } \\
\text { Unsymmetrically } \\
\text { Reinforced Concrete } \\
\text { Beams; Moment- } \\
\text { curvature Analysis; } \\
\text { Cracked Stiffness }\end{array}$ & $\begin{array}{l}\text { study focuses on strength and deformation capacity prediction of } \\
\text { unsymmetrically RC members at yield which primarily required for the design } \\
\text { and assessment. In the study, wide range of RC sections are generated and } \\
\text { analyzed using different section dimensions, material types, reinforcement } \\
\text { ratios and configurations to reveal behavior of these members. Influence of } \\
\text { parameters on the responses is investigated and they are contributed to } \\
\text { prediction equations by statistical evaluations. Prediction equations are first } \\
\text { tested with analytical RC section results and comparisons have shown very } \\
\text { good agreement. Equations are then applied to predict dynamic features of two } \\
\text { experimental MDOF buildings. Evaluations have revealed the reliability of } \\
\text { prediction equations in approximation of responses in building scale. }\end{array}$ \\
\hline
\end{tabular}

(C) 2019 MIM Research Group. All rights reserved.

\section{Introduction}

Structural behavior is strongly affected from structural member responses and both design and performance assessment of structures requires the determination of flexural strength capacity of members. If the structural member has adequate strength and the demand is lower than strength capacity, response is elastic. However, nonlinear deformations occur if the strength of members is exceeded and nonlinear deformation capacity is affected from the efficiency of member confinement for reinforced concrete (RC) members. On the other hand, design of structures requires the flexural strength capacity of members since it is expected that elastic demands (shear forces, bending moment etc.) should always be lower than the capacity of members.

In addition to design or assessment of structures, strength capacity of members has also crucial role in determination of dynamic characteristics (e.g. natural vibration period) of buildings since elastic stiffness (or cracked stiffness) of the members are strongly affected from capacity of member at yield level. Stiffness of members at elastic region can be obtained by moment-curvature (so called as $m-\phi$ ) analysis. Section dimensions, reinforcement details, strength of materials and their behavior should be defined to perform $m-\phi$ analysis. Although it is rapid to get results from $m-\phi$ analysis in today's computers, it becomes time-consuming and exhausting for complex structures which have high amount of input data. Other than complex analysis methods, simplified

\footnotetext{
*Corresponding author: mehmetpalanci@arel.edu.tr

a orcid.org/0000-0002-9223-5629

DOI: http://dx.doi.org/10.17515/resm2019.141st0802

Res. Eng. Struct. Mat. Vol. 6 Iss. 2 (2020) 105-118
} 
analytical or numerical approaches [1-5] can also be used to determine strength and deformation capacity of members. These approaches significantly increase time saving, but they are mostly concentrated on symmetrically RC members. It is known fact that RC structures are not only composite of symmetrically reinforced members and RC beams are frequently designed as unsymmetrically reinforced due to combined effects of dead, live and earthquake loads. Although behavior of these elements are simpler than columns as the axial load is omitted, combined effects of section dimensions, longitudinal reinforcement ratio (compression and tension) and strength of materials has uttermost importance on the flexural response of these members. Flexural response of unsymmetrically RC elements is also important to exhibit damage mechanism of beamcolumn joints and hence the structural behavior. If the sum of strength of beams is higher than strength capacity of columns, damage is expected to occur at column critical regions or vice versa. Similar approximation is also followed during the design phase of beamcolumn joints, but it is obligated that strength of columns should be higher than beams due to strong column-weak beam philosophy.

Estimation of cracked stiffness (i.e. flexural strength) of RC members are also increasingly becoming important topic in modern seismic codes (e.g. Eurocode-8 [6] and Turkish Building Earthquake Code (TBEC) 2018 [7]) to determine behavior in member and/or structural content. In the codes, various cracked stiffness values are recommended for different type of members such as columns and beams. Besides the fixed values, simplified equations are also provided to estimate cracked stiffness of members. However, these equations also need to determine flexural capacity of members since these equations involve the flexural strength and rotation capacity of members at yield.

All issues stated above clearly show that strength and hence stiffness of unsymmetrically reinforced concrete members has crucial role in both design and performance assessment of new and existing structures. For this reason, this study is aimed to propose prediction equations to express flexural strength and deformation capacity of unsymmetrically reinforced (RC) members at yield level. During the designation of prediction equations, wide range of RC sections are generated for different section dimensions, reinforcement ratios and material types to cover all possible cases. All generated RC members are then subjected to $m-\phi$ analysis. Effect of all considered structural attributes are evaluated considering the analysis results and then prediction equations are obtained by statistical interpretations. Proposed equations are then applied to simulated RC sections and compared with $m-\phi$ analysis results. In addition, dynamic characteristics of experimental building and different analytical multi-degree of freedom (MDOF) buildings are projected using provided equations.

\section{Description of Modeling Assumptions and Analytical RC Beams}

In Fig. 1, behavior of materials (unconfined concrete and reinforcement) used in this study are plotted. It can be said that constitutive laws for concrete and reinforcements are represented by Modified Kent Park [8] and Mander [9] model, respectively. In the figure, tensile strength of reinforcement and compression of unconfined concrete and their corresponding strains is described by notations of $\left(f_{c}, \varepsilon_{c o}\right)$ and $\left(f_{y}, \varepsilon_{s y}\right)$, respectively. Ultimate strength of reinforcement is notated as $f_{\text {su. }}$. In the study, young modulus of steel $\left(E_{s}\right)$ is taken $2 \times 10^{5} \mathrm{MPa}$. Yield strain $\left(\varepsilon_{s y}\right)$ is obtained by proportion of $f_{y}$ and $E_{s}$ which is the elastic slope of reinforcement. It is worth to remind that behavior of both materials after yield level have no significant importance since the capacity of members at yield level is investigated. 
During the analysis of sections, neutral axis depth $\left(c_{n}\right)$, curvature $(\phi)$ and moment $(M)$ is obtained using material behaviors shown in Fig. 1 for each increments of strain values until the predefined strain values are (i.e. stopping criteria) developed. Flexural strength $\left(M_{y}\right)$ and curvature $\left(\phi_{y}\right)$ at yield is determined when the stopping criteria, assigned to extreme fibre concrete compression strain of 0.004 and extreme tension reinforcing bar strain of 0.015 according to Priestley et al. [10], is reached.
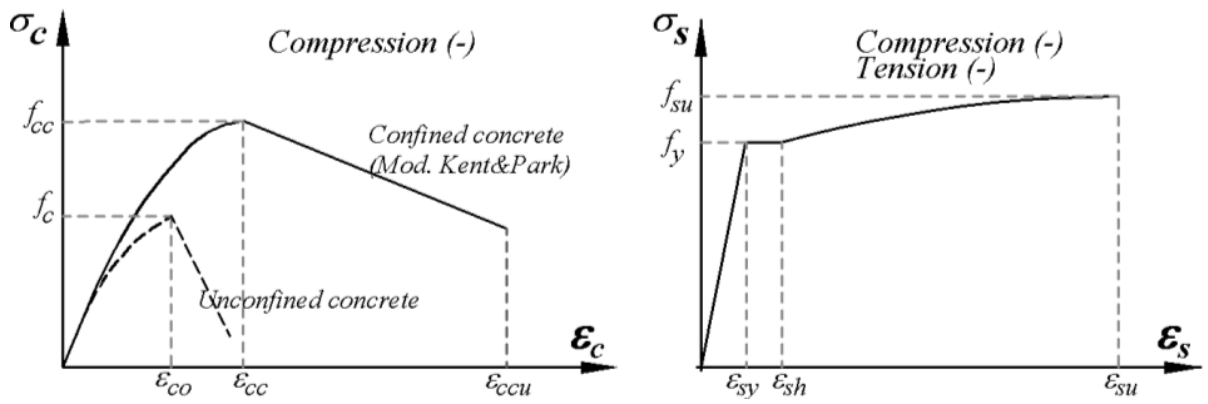

Fig. 1 Constitutive laws for materials used in $m-\phi$ analysis (Left: confined and unconfined concrete [8], Right: reinforcement [9])

In this study, beam width is taken between $250 \mathrm{~mm}$ and $350 \mathrm{~mm}$ with increment of $50 \mathrm{~mm}$. Section height is determined according to $H / B$ ratio and this ratio is arranged between 1 and 4. Later, analytical RC sections are diversified by concrete compressive strength $\left(f_{c}\right)$, longitudinal reinforcement ratio $\left(\rho_{l}\right)$, mechanical reinforcement ratio $\left(w^{\prime} / w\right)$ and steel grade type (S220 and S420). It is worth to remind that, similar to Eurocode 8 [6], $w$ and $w^{\prime}$ terms describe the mechanical reinforcement ratio of the tension (including the web reinforcement) and compression, respectively, longitudinal reinforcement. In the scope of study, more than 20,000 unsymmetrically reinforced analytical RC sections are considered and general attributes of generated analytical RC sections are given in Table 1. In addition to features of sections given in Table 1, RC sections are altered by different web reinforcement configurations. By this way, possibility of all cases is considered in the study.

Table 1 Range of parameters considered in generation of unsymmetrically RC sections

\begin{tabular}{ccccccc}
\hline \multirow{5}{*}{ Parameters } & \multicolumn{5}{c}{ Geometry of RC beams } \\
\cline { 2 - 7 } & \multicolumn{7}{c}{ Square } & Min & Max & Increment \\
\cline { 2 - 7 } & Min & Increment & $1 \%$ & $1 \%$ & $4 \%$ & $1 \%$ \\
\hline$\rho_{l}$ & $1 \%$ & $4 \%$ & 5 & 10 & 35 & 5 \\
$f_{c}(\mathrm{MPa})$ & 10 & 35 & - & 220 & 420 & - \\
$f_{y}(\mathrm{MPa})$ & 220 & 420 & 50 & 250 & 350 & 50 \\
$B(\mathrm{~mm})$ & 250 & 350 & 50 & 500 & 1000 & 100 \\
$H(\mathrm{~mm})$ & 250 & 350 & & &
\end{tabular}

\section{Sectional Attributes on the Response of Unsymmetrically RC Beams}

In order to investigate effect of section dimensions on the flexural response of $\mathrm{RC}$ sections, rectangular type members are used. In Fig. 2, relation between flexural strength $\left(M_{y}\right)$ and section dimensions $(B$ and $H)$ is illustrated. It can be seen from the figure that section dimensions have significant contribution on the strength capacity of members and they can be involved in prediction equations. Palanci [4] showed that correlation 
between $B H^{2}$ which includes combination of both dimensions, and moment capacity $\left(M_{y}\right)$ of sections is satisfactory. For this reason, correlation between $B H^{2}$ and $M_{y}$ values are compared in Fig. 2c. It can be observed from Fig. 2c that $B H^{2}$ is promising to exhibit relation with moment capacity of members compared to individual section dimensions

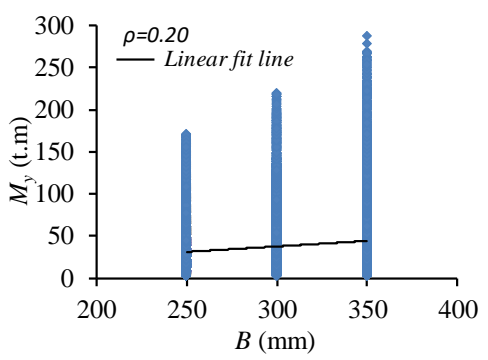

(a)

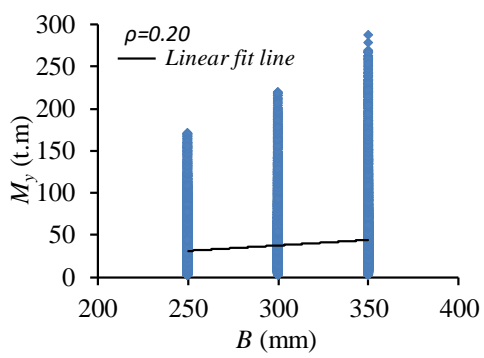

(b)

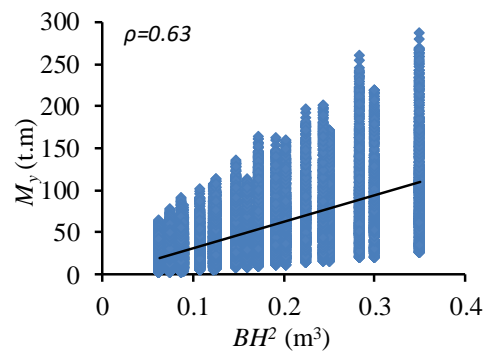

(c)

Fig. 2 Correlation between section properties and $M_{y}$ (a: width $(B)$, b: height $(H)$, c: $B H^{2}$ )
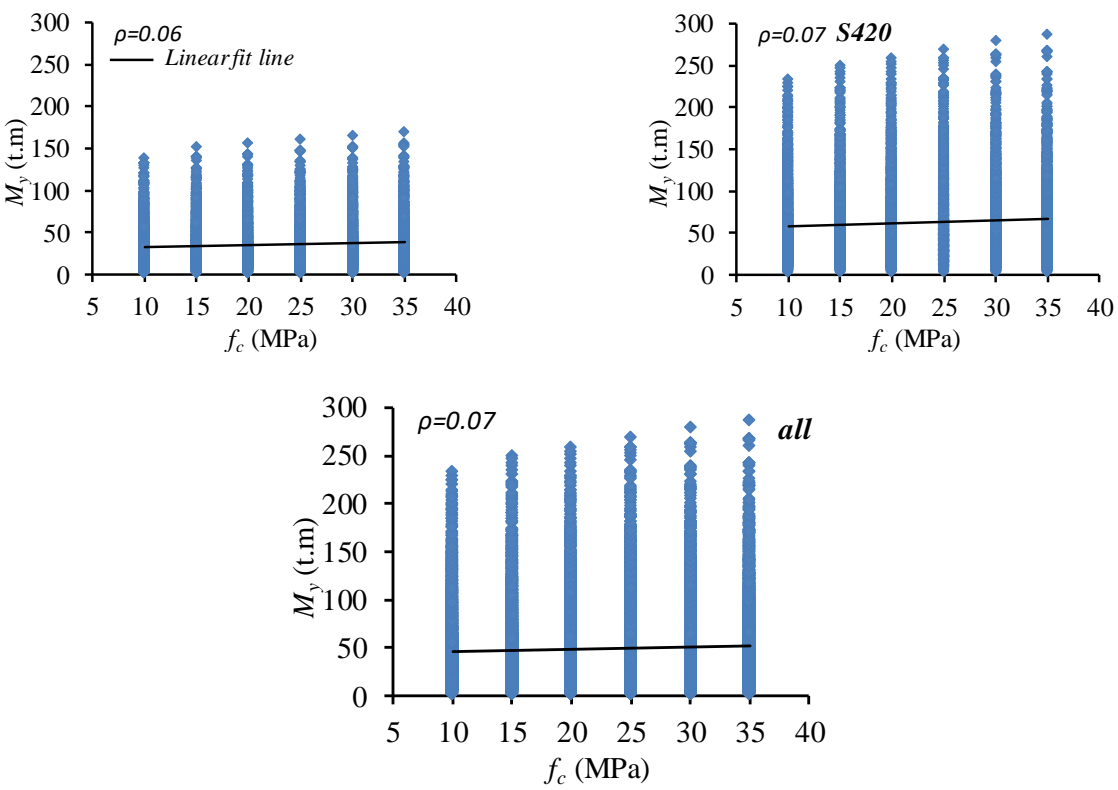

Fig. 3 Correlation between compressive concrete strength and $M_{y}$ 
In Fig. 3, relation of compressive concrete strength and moment capacity of section is illustrated for distinct steel grade type. It can be understood from the figure that compressive concrete strength type has no significant impact on the moment capacity of unsymmetrically RC members. However, it can be implied that moment capacities of sections which have S420 steel grade is higher than that of sections which have S220 steel grade.

It is real fact that longitudinal reinforcement ratio $\left(\rho_{l}\right)$ significantly affects the strength capacity of RC members. In order to observe efficiency of $\rho_{l}$ on the unsymmetrically RC sections, relation between $\rho_{l}$ and $M_{y}$ is observed in Fig. 4. Figure indicates that moment capacity of RC members is increasing with increasing longitudinal reinforcement ratio. It is worth to reminded relation of $\rho_{l}$ and $M_{y}$ is also investigated for S220 and S420 grades, respectively. Investigations have also revealed that higher correlations can be observed if the relation between $\rho_{l}$ and $M_{y}$ is studied for each steel grade type individually. Furthermore, it can be expressed that correlation between $\rho_{l}$ and $M_{y}$ parameters is satisfactory.

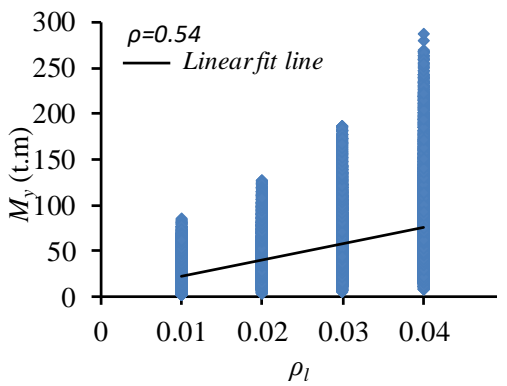

Fig. 4 Relation of $\rho_{l}$ and $M_{y}$ for all RC beams

During the evaluation of sectional attributes on the moment capacities of unsymmetrically RC sections, effect of mechanical reinforcement ratio is not considered. For this reason, effect of mechanical reinforcement ratio $\left(w^{\prime} / w\right)$ on the flexural strength capacity $\left(M_{y}\right)$ of the members is investigated separately. In Fig. 5, relation between $w^{\prime} / w$ and $M_{y}$ is plotted for distinct steel grade types and the extreme values of longitudinal reinforcement ratio, respectively. In general, it can be said that moment capacities of RC sections are inversely proportional to mechanical reinforcement ratios and relation is likely exponential between these two parameters. It can be also told that effect of steel grade type is not apparent on the relation. However, relation between these parameters significantly declines with increasing longitudinal reinforcement ratio. 


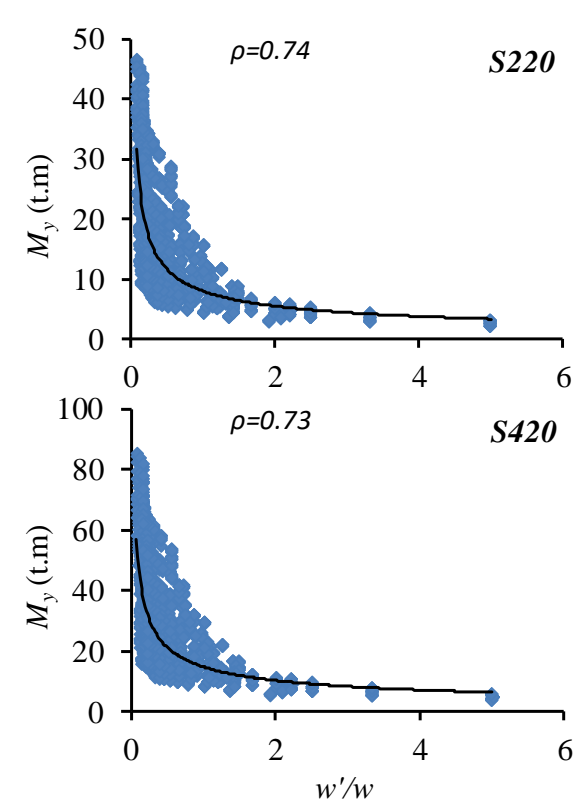

(a)

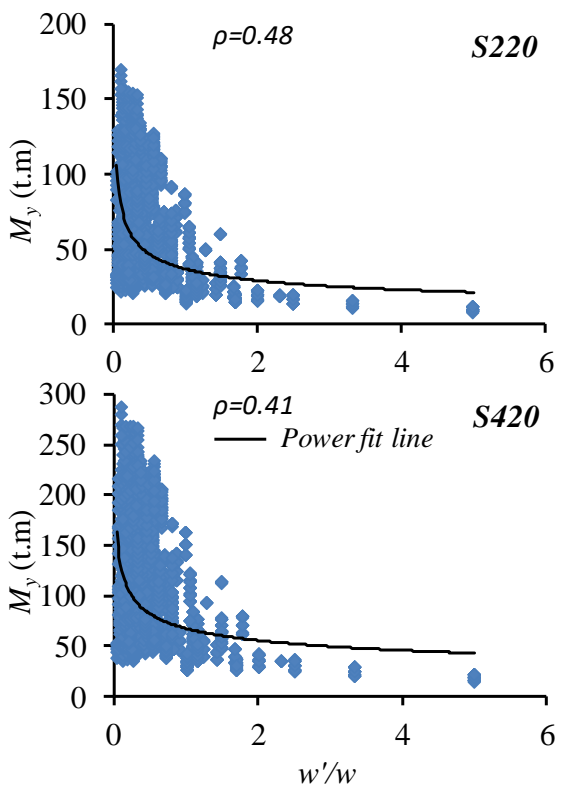

(b)

Fig. 5 Relation between $w^{\prime} / w$ and $M_{y}\left(\mathbf{a}: \rho_{l}=1 \%\right.$, b: $\left.\rho_{l}=4 \%\right)$

It was realized in statistical evaluations that $A_{s}{ }^{\prime} / A_{s}$ ratio has important contribution on moment capacities of unsymmetrically RC members. $A_{s}^{\prime} / A_{s}$ describes the ratio of extreme compression longitudinal reinforcement to extreme tension longitudinal reinforcement area (note that web longitudinal reinforcement is not included). For this reason, relation between $A_{s}{ }^{\prime} / A_{s}$ and $M_{y}$ is also studied to make further investigation. In Fig. 6, effect of distinct longitudinal reinforcement ratios is shown in different columns and steel grade types are illustrated in two rows to investigate correlation between $A_{s}{ }^{\prime} / A_{s}$ and $M_{y}$. By this way, combined effects are explored. In addition, effect of extreme values of section dimension ratios $(H / B)$ is included to make detailed assessment. It can be seen from the figure that longitudinal reinforcement ratio significantly affects the trend of moment capacities.

It can be admitted that high longitudinal reinforcement ratios dramatically influenced the relation between $A_{s}{ }^{\prime} / A_{s}$ and $M_{y}$. Hence, $A_{s}{ }^{\prime} / A_{s}$ becomes distinguishing parameter for high longitudinal reinforcement ratio. For $A_{s}{ }^{\prime} / A_{s}$ values lower than one, moment capacity of RC sections is increasing with increasing $A_{s}{ }^{\prime} / A_{s}$. However, this situation is reversed if $A_{s}{ }^{\prime} / A_{s}$ is higher than one. Nevertheless, it can be told that relation between As'/As and $M_{y}$ seems more promising than relation between $w^{\prime} / w$ and $M_{y}$ in general. In addition, when the distribution of $w^{\prime} / w$ and $A_{s}^{\prime} / A_{s}$ with $M_{y}$ is compared, it can clearly be said that distribution of $w^{\prime} / w$ is much more dispersed and this situation is an important obstacle for the definition of prediction equation. 

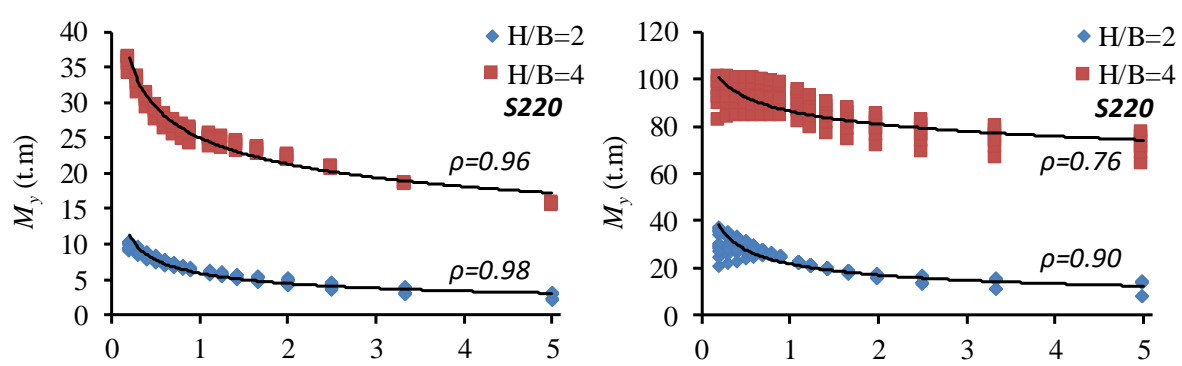

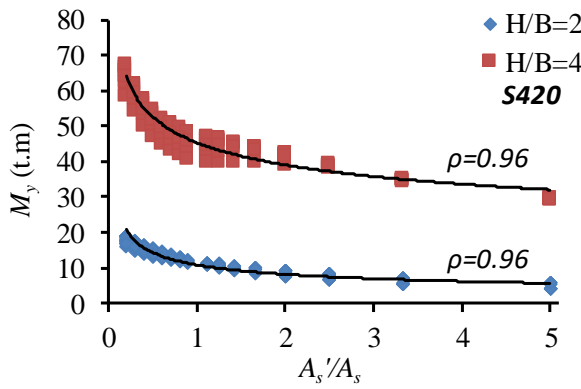

(a)

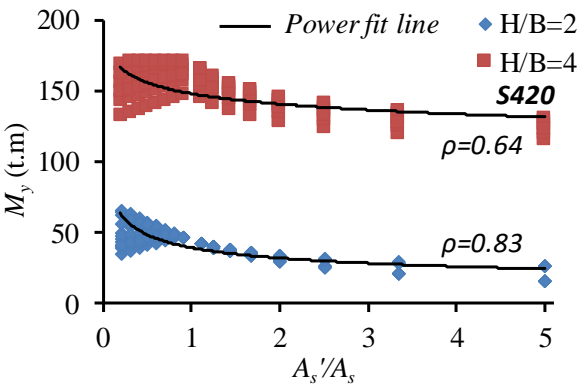

(b)

Fig. 6 Relation of $A_{s}{ }^{\prime} / A_{s}$ and $M_{y}$ (a: $\rho_{l}=1 \%$, b: $\rho_{l}=4 \%$ )

\section{Mathematical Expression for Unsymmetrically RC Member Responses at Yield}

During the development of mathematical equations, it was aimed to involve all parameters (e.g. strength of materials, section dimensions, amount of reinforcement ratio and etc.) as much as possible which primarily affect the strength and deformation capacity of members. By this way, possibility of changes in section dimensions or strain and/or strength of materials due to exposure of corrosion, moisture and other related issues which in long term dramatically influence behavior of materials and hence the strength and deformation capacity of members are taken into account. Investigations in Section 3 have also revealed that $B H^{2}, \rho_{l}$, yield strength of reinforcement $\left(f_{y}\right)$ and $A_{s}{ }^{\prime} / A_{s}$ have primary contribution on the flexural strength of unsymmetrically RC members. It should be reminded that during the evaluations for the determination of these parameters, the full bond mechanism between concrete and reinforcement is assumed and also it is accepted that longitudinal reinforcement bars are homogeneously distributed along the section.

After determination of parameters, statistical evaluations were made to finalize the equation using nonlinear optimization algorithm: generalized reduced gradient (GRG) algorithm via Excel spreadsheet solver. During the iteration process, it was aimed to minimize the variation between predictions and actual data. In addition, it was assumed that predicted/actual values are normally distributed and exceedance probability of both tails in the distribution was limited to $5 \%$. In other words, the constraint was used to enforce prediction equation to estimate value that falls in $90 \%$ occurrence probability of actual data. Consequently, equations and their multipliers are determined considering all constraints (limitations). Consequently, mathematical expression for flexural strength capacity $\left(M_{y}\right)$ of unsymmetrically RC beams suggested in this study is given in Eq. (1).

$$
M_{y}=\left(60 \frac{f_{y}}{220}\right) B H^{2} \rho_{l}^{0.9}\left(\frac{A_{s}^{\prime}}{A_{s}}\right)^{\alpha}(N-m m)
$$


Notation of $\alpha$ is described to distinguish ratio of compression and tension reinforcement. If $A_{s}^{\prime} / A_{s}$ is higher than one, then $\alpha$ is equal to -0.3 and -0.1 if vice versa. The most advantageous aspect of the equation is that it is direct, simple and appropriate to spreadsheet applications. Since it considers the most important and very easily determined parameters, it can be used in practical to estimate moment capacities. Although generalized rules are applied for the construction of RC members, Eq. (1) neglects the effect of depth of concrete cover on flexural strength capacity.

It is also worth to remind that Eq. (2) is used in prediction of flexural strength capacity of $\mathrm{RC}$ beams for approximate estimations especially in design phase of RC structures. In the equation, $A_{s}, d$ and $d^{\prime}$ is the tensile longitudinal reinforcement area, section height minus concrete cover and concrete cover, respectively. Concrete cover here is described as distance from the extreme fiber to center of longitudinal reinforcement bar. It should be noted that the most important deficiency of this equation is that it neglects the difference between the moment capacities of beams having the same reinforcement area but different beam widths. In the study, moment capacities obtained according to Eq. (1) and Eq. (2) is also compared with moment capacities determined from moment-curvature analysis in forthcoming section, separately.

$$
M_{y}=A_{s} f_{y}\left(d-d^{\prime}\right)
$$

Curvature is another parameter to describe unsymmetrically $\mathrm{RC}$ beam responses at yield. According to Priestley et al. [10] yield curvature is the $K$ times of the proportion of yield strain of longitudinal reinforcement $\left(\varepsilon_{s y}\right)$ to section height. $K$ is the coefficient value that depends on geometric features and structural member type such as beam or column. However, Palanci [4] stressed the high dispersion of this expression and stressed that Priestley et al. [10] expression may lead to overestimate yield capacities especially with increasing axial load ratio $(v)$. Accordingly, yield curvature capacity of RC sections is calculated by Eq. (3) suggested by Palanci [4]. Statistical evaluations performed by Palanci [4] have shown that yield curvature depends on the axial load level and longitudinal reinforcement ratio of members. In addition, the relation between these parameters and yield curvature was described in polynomial function. Using the appropriate function curve with spreadsheet solver, Eq. (3) is finally provided. In the equation, axial load ratio $(v)$ can be assumed zero for both symmetrically and unsymmetrically RC beams and Eq. (3) can be calculated accordingly.

$$
\phi_{y}=2.0 \frac{\varepsilon_{s y}}{H}\left[-2.75(v)^{2}+1.30(v)+0.90\right]\left[5.50 \rho_{l}+0.90\right]
$$

The pros of Eq. (3) are it is applicable to variety of members such as beams and columns and it is very practical to estimate yield curvature. However, equation is just valid for square or rectangular RC sections.

Consequently, flowchart for the application of mathematical expressions to determine flexural strength and yield curvature capacity of unsymmetrically RC members can be followed by Fig. 7. In the figure, details about calculation of parameters for each step are clearly shown. It should be reminded that $H$ describes the section dimension parallel to earthquake (i.e. seismic force or excitation) direction. 


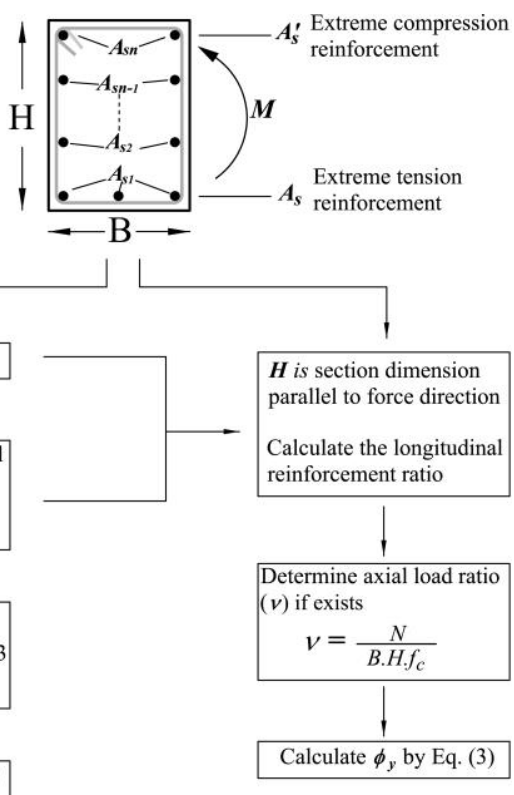

Fig. 7 Flowchart for the calculation of $M_{y}$ and $\phi_{y}$

\subsection{Comparison of Prediction Equations with Sectional Responses}

In Fig. 8, correlation between Eq. (1) and $m-\phi$ results and distribution of $M_{y, E q .(1)} / M_{y, m-\phi}$ ratios are plotted. In order to make statistical evaluations some salient statistical parameters such as mean, median and coefficient of variation $(\mathrm{CoV})$ is also provided. Comparison of mean and median values might be useful when the $\mathrm{CoV}$ is high. Furthermore, it can be said that close relation between the mean and median values emphases the reliability of predictions.
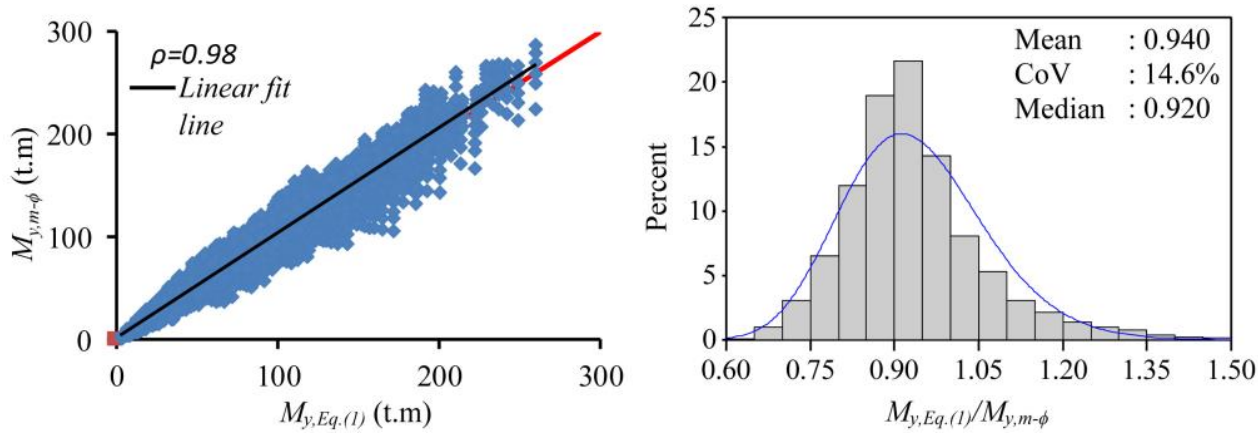

Fig. 8 Comparison of flexural strength determined from $m-\phi$ analysis and Eq. (1)

It can be understood from the Fig. 8 that correlation coefficient is very high (0.98) between $m-\phi$ analysis and Eq. (1) results. It can also be seen that mean (0.94) and median (0.92) values of $M_{y, E q .(1)} / M_{y, m-\phi}$ ratio is very close to each other. Comparisons clearly have shown that proposed equations highly satisfactory to express the moment capacities of unsymmetrically RC beams at yield. The $\operatorname{CoV}(0.146)$ of $M_{y, E q .(1)} / M_{y, m-\phi}$ is also very low and this situation is also another indicator of reliable estimations.

In Fig. 9, Eq. (2) predictions and $m-\phi$ results are also compared using mean, median and $\mathrm{CoV}$ parameters. It can clearly be viewed from the Fig. 9 that Eq. 2 mostly underestimates 
(0.59) the moment capacity of RC beams. Difference is around $41 \%$ and this endangers the reliability of equation. Comparison of $M_{y, E q .(2)}$ and $M_{y, m-\phi}$ results is also manifest the dispersion of results and thus $\operatorname{CoV}$ of $M_{y, E q .(2)} / M_{y, m-\phi}$ is very high (40\%). One may think that prediction of Eq. (2) may be improved when the steel grade type and longitudinal reinforcement ratios are separately investigated. For this purpose, correlation coefficient, $\mathrm{CoV}$ and $M_{y, E q .(2)} / M_{y, m-\phi}$ are studied for each $\rho \mathrm{l}$ and steel grade type. Results have indicated that relation of $M_{y, E q .(2)}$ and $M_{y, m-\phi}$ is fluctuated and $\mathrm{CoV}$ is generally higher than $30 \%$.
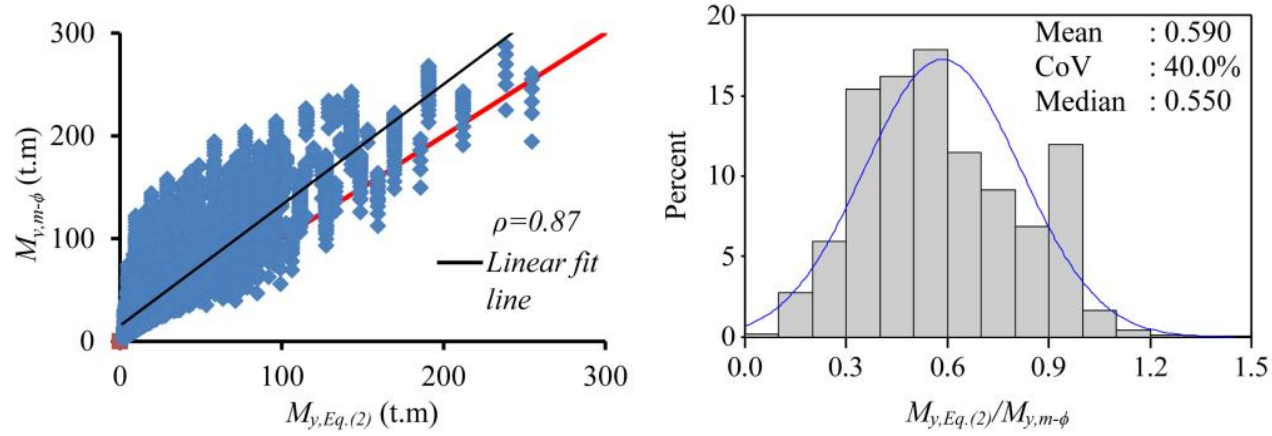

Fig. 9 Comparison of flexural strength determined from $m-\phi$ analysis and Eq. (2)

\subsection{Estimation of Dynamic Characteristics of MDOF Buildings Using Prediction Equations}

In order to study efficiency of provided equations, vibration periods which reflect the dynamic features of the structure of two experimental MDOF buildings are predicted. For this purpose, cracked stiffness of beams and columns in MDOF buildings are calculated by Eq. (4). In the equation, $M_{y}, \theta_{y}$ and $L_{s}$ describe the mean yield strength and chord rotation capacity at the both ends and shear span length of the member, respectively. Chord rotation capacities can also be calculated by Eq. (5). In the equation, $d_{b}$ is the (mean) diameter of the tension reinforcement. During the calculations for experimental buildings, $M_{y}$ and $\phi_{y}$ values are obtained by Eq. (1) and Eq. (3) and then cracked stiffness of symmetrically and unsymmetrically RC members are calculated via Eqs. (4) and (5). The reader is referred to see Palanci $[4,11]$ for flexural strength capacity of ordinary RC columns. Calculated cracked stiffness values were then implemented to analytical models and dynamic features of models were obtained to compare with experimental MDOF building results.

$$
\begin{aligned}
& E I_{\text {eff }}=\frac{M_{y} L_{s}}{3 \theta_{y}} \\
& \theta_{y}=\frac{\phi_{y} L_{s}}{3}+0.0013\left(1+1.5 \frac{H}{L_{s}}\right)+0.13 \phi_{y} \frac{d_{b} f_{y}}{\sqrt{f_{c}}}
\end{aligned}
$$

Provided equations are first practiced on full-scale, 2D four-story ICONS bare frame. The frame was produced to reflect construction practices used in southern European countries in the 1950's and it was tested at the ELSA laboratory (Joint Research Centre, Ispra). Further information about the ICONS can be found in Pinho and Elnashai [12] and Varum [13]. Structural model of the experimental building is prepared using SAP2000 [14] and shown in Fig. 10. It can be seen from the figure that model consists model consists of a three-bay RC frame with varying lengths, but all stories have identical $(2.70 \mathrm{~m})$ story height. Further information about the sectional attributes of the RC members can be found from Varum [13]. 
Experimental bare frame was tested under earthquake levels that have returned periods of 475 and 975 years. It was observed during the tests that significant damage, such as full-width cracks or concrete spalling, is not observed [12]. In addition, Pinho and Elnashai [12] carried out non-linear dynamic analysis of frame model and they pointed out that building behaved satisfactory under input motion that have return period of 475 years although local hinging is recorded. However, high level of damage is stressed under return period of 975 years at different stories of building due to large deformation demand of strong-column. According to analytical analysis results of Pinho and Elneshai [12], dominant (first) inelastic vibration period of the building is $1.1 \mathrm{~s}$ and $1.4 \mathrm{~s}$ for return periods of 475 and 975 years. Considering the numerical and experimental test results $[12,13]$, it can be assumed that inelastic vibration of the building is likely to be somewhere close to the return period of 975 years results. For this purpose, first 4 equivalent modal frequency of bare frame provided by Varum [13] from the test for the return period of 975 years is determined approximately. Accordingly, first 4 equivalent modal frequency of bare frame is approximated $0.7 \mathrm{~Hz}(1.43 \mathrm{~s}), 2.18 \mathrm{~Hz}(0.46 \mathrm{~s}), 3.06 \mathrm{~Hz}$ $(0.33 \mathrm{~s})$ and $6.76 \mathrm{~Hz}(0.15 \mathrm{~s})$, respectively. It is worth to note that determined frequencies approximately correspond to $0.75 \%$ of roof drift ratio and dominant period approximated from the test results is also very close to inelastic period of Pinho and Elnashai [12].

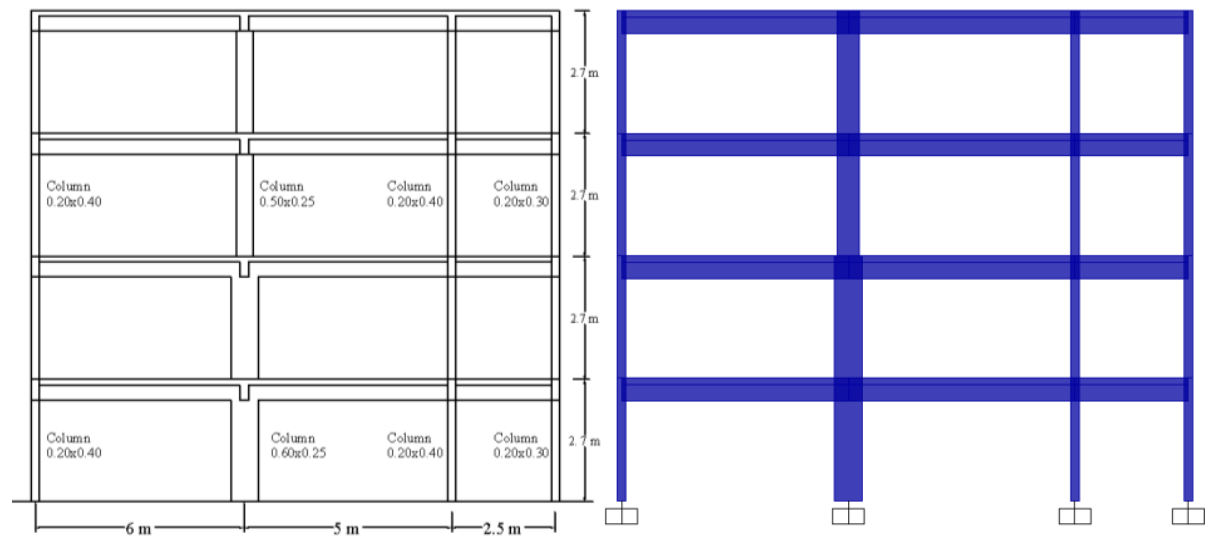

Fig. 10 Building elevation of ICONS RC bare frame and 2D analysis model

After implementation of cracked stiffness of members to bare frame, first 4 natural vibration period of the building is also obtained from 2D analytical model shown in Fig. 10 using prediction equations. Obtained values are given in Table 2 with experimental test results for comparison purposes. It can be seen from the table that analytical model periods are very close to results of experimental test results. Difference between the dominant periods is lower than $1 \%$. It seems that differences are increasing at high modes but it is still an acceptable range and it can be admitted that analytical model results have very good agreement with test results.

Second practice is also made again on three-story, three-dimensional RC building also called the SPEAR building (see Fig. 11). The test building was designed only for gravity loads without earthquake resistance to represent older construction in Southern European Countries. Further details about the SPEAR test building procedure and construction, mechanical features of the building materials and reinforcement details can be found in Jeong and Elnashai [15], Mola et al. [16], Molina et al. [17] and Negro et al. [18]. 
Table 2 Comparison of first 4 natural vibration periods of analytical model and ICONS bare frame

\begin{tabular}{ccccc}
\hline & $1^{\text {st }}$ period $(\mathrm{s})$ & $2^{\text {nd }}$ period $(\mathrm{s})$ & $3^{\text {th }}$ period $(\mathrm{s})$ & $4^{\text {th }}$ period (s) \\
\hline ICONS Test & 1.43 & 0.46 & 0.33 & 0.15 \\
This study & 1.44 & 0.48 & 0.28 & 0.19 \\
Difference (\%) & 0.70 & 4.35 & 17.86 & 26.67 \\
\hline
\end{tabular}

It can be seen from the figure that building is irregular in plan but story height of each floor is same $(3 \mathrm{~m})$ which can be said regular in height. Section dimension of RC columns is mainly $0.25 \times 0.25 \mathrm{~m}$ except that one RC column is $0.25 \times 0.75$ per floor and RC beams are identical $(0.25 \times 0.50 \mathrm{~m})$. The test building was subjected to PGA levels of $0.02 \mathrm{~g}$ and $0.15 \mathrm{~g}$ which can be described as low and high level of excitations along two orthogonal directions (i.e. bi-directional excitations) and general engineering demand parameters (EDP) such as displacement history of floors, member internal forces and deformations were recorded in time domain. The test results of experimental building are provided in many studies [18-20] including modal characteristics of building.

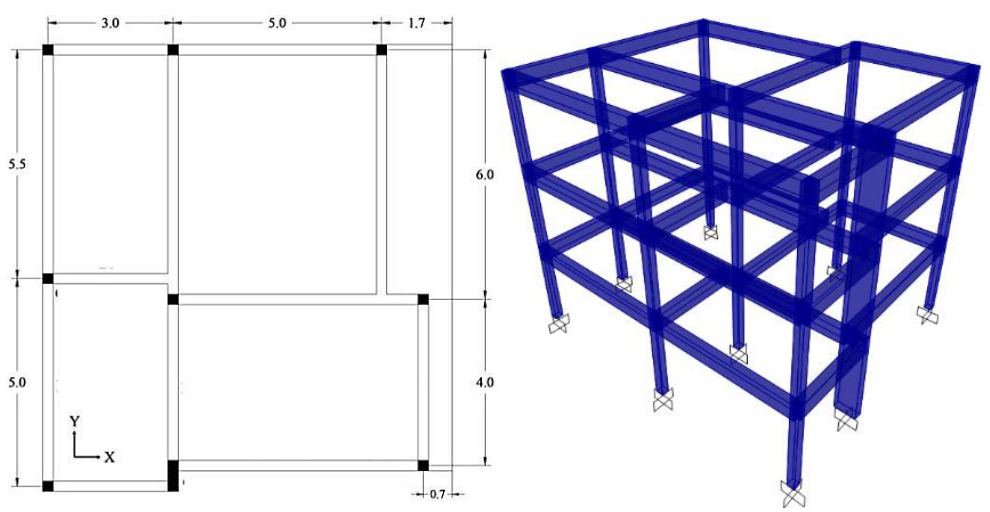

Fig. 11 Plan view (Left) and 3D structural model (Right) of three-story SPEAR building (Units in meter)

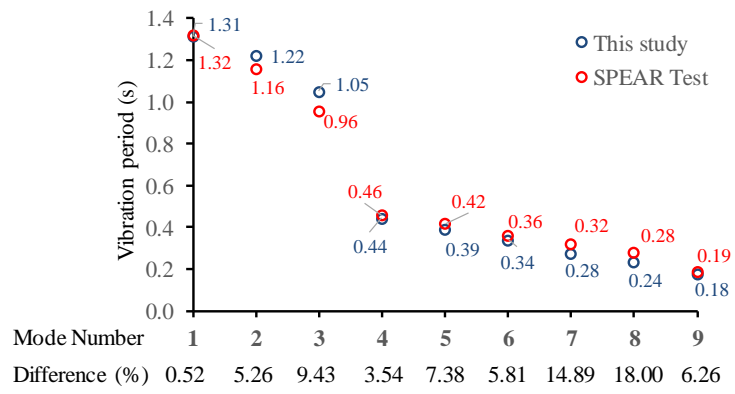

Fig. 12 Comparison of 3D analytical and experimental modal analysis results for $0.15 \mathrm{~g}$ test

In order to make comparison of modal characteristics of test building, 3D view of analytical model is prepared by SAP2000 [14] as shown in Fig. 11 (right) and cracked stiffness of structural members are determined under provided sectional features of the members. Obtained member stiffness values are implemented building and compared 
with test results for high level $(0.15 \mathrm{~g})$ excitation (see Fig. 12). Selection of this level is based on the study of Avsar et al. [21] since they stress that member response is far from the section yield level and cracking of members are limited. Analytical model results and tests results are compared for 9 mode shapes of the building and percent difference between them is also shown in the figure. Comparisons clearly show very good fit between the results which, in other words, reveals the reliability of proposed equations.

\section{Conclusions}

In this study, prediction equations are provided to estimate cracked stiffness and hence the flexural strength capacity of unsymmetrically RC members at yield. For this purpose, wide range of section dimensions, material types, reinforcement ratios and configurations are covered, analyzed and statistically evaluated. Influence of parameters on the response of unsymmetrically $\mathrm{RC}$ members is investigated and implemented to prediction equations by extensive statistical treatments. Prediction equations are first tested with individual sections analytical RC section results and comparisons have shown very good agreement. In addition, mode shapes (periods) that represent the dynamic characteristics of full scale two experimental building is projected by using prediction equations. Comparisons have also shown that dynamic characteristics of the analytical models which stiffness of the members formed by provided equations have very good matching with experimental building results. Furthermore, it can be admitted that provided equations are capable of approximation of responses in building scale. Consequently, it can be said that results of this study have proved that proposed equations can be used to determine flexural strength and stiffness of unsymmetrically reinforced members reliably. Some important implications of the study can be expressed as follows:

- Statistical evaluations have shown that combination of section dimension $\left(B H^{2}\right)$ is more promising in determination of relation between $M_{y}$ than that of individual dimensions.

- It is observed that mechanical reinforcement ratio $\left(w^{\prime} / w\right)$ which includes the web reinforcement is inversely proportional to moment capacities of RC sections and relation is exponential. It can also be said that correlation between ratio of compression reinforcement to tension reinforcement $\left(A_{s}{ }^{\prime} / A_{s}\right)$ and $M_{y}$ is higher than $w^{\prime} / w$.

- $B H^{2}$, longitudinal reinforcement ratio $\left(\rho_{l}\right)$, yield strength capacity of reinforcement $\left(f_{y}\right)$ and $A_{s}^{\prime} / A_{s}$ are found adequate to express flexural capacity of unsymmetrically reinforced concrete members.

- It can be expressed that proposed equations can be used with numerical and analytical approaches proposed for symmetrically RC members to predict dynamic response of real buildings.

\section{References}

[1] Chandrasekaran S, Nunziante L, Serino G and Carannante F. Curvature Ductility of RC Sections Based on Eurocode: Analytical Procedure. KSCE J Civ Eng. 2011; 15(1): 131 144. https://doi.org/10.1007/s12205-011-0729-4

[2] Colajanni P, Fossetti M and Papia M. An Analytical Step-by-Step Procedure to Derive the Flexural Response of RC Sections in Compression. Advances in Civil Engineering. 2013; Article ID 275657: 1-13. http://dx.doi.org/10.1155/2013/275657

[3] Naderpour, H. and Mirrashid, M. Moment capacity estimation of spirally reinforced concrete columns using ANFIS. Complex and Intelligent Systems. 2019. https://doi.org/10.1007/s40747-019-00118-2 
[4] Palanci, M. Flexural response prediction of reinforced concrete members based on statistical observations. Arabian Journal for Science and Engineering. 2017; 42(9): 3689-3709. https://doi.org/10.1007/s13369-016-2392-z

[5] Panagiotakos TB, Fardis MN. Deformations of reinforced concrete members at yielding and ultimate. ACI Structural Journal. 2001; 98: 135-148. https://doi.org/10.14359/10181

[6] Eurocode 8. Design provisions for earthquake resistance of structures, Part 3: Assessment and retrofitting of buildings. European Committee for Standardization, Brussels; 2003

[7] TBEC. Turkish Building Earthquake Code, Disaster and Emergency Management Presidency, Ankara; 2018.

[8] Scott BD, Park R and Priestley MJN. Stress-strain behavior of concrete confined by overlapping hoops at low and high strain rates, ACI J. 1982; 79(1): 13-27. https://doi.org/10.14359/10875

[9] Mander J. (1984). Seismic design of bridge piers. Ph.D. Dissertation, University of Canterbury, New Zealand.

[10] Priestley MJN, Calvi GM, Kowalsky MJ. Displacement Based Seismic Design of Structures. IUSS Press, Pavia, 2007.

[11] Palanci, M. Flexural Strength Estimation of Ordinary Rectangular Reinforced Concrete Sections. Proceedings of the 3th International Conference on Civil and Environmental Engineering, Çeșme, Paper No. 387, 2018.

[12] Pinho R and Elnashai AS. Dynamic collapse testing of a full-scale four storey RC frame, ISET Journal of Earthquake Technology. 2000; 37(4): 143-164.

[13] Varum H. (2003). Seismic Assessment, Strengthening and Repair of Existing Buildings. Ph.D. Dissertation, University of Aveiro, Portugal.

[14] SAP2000, Integrated finite element analysis and design of structures basic analysis reference manual. Computers and Structures Inc., Berkeley, California (USA).

[15] Jeong SH, Elnashai AS. Analytical assessment of an irregular RC full scale 3D test structure, Mid-America Earthquake Centre, (MAE) Report, University of Illinois at Urbana-Champaign, CD Release 04-03, USA, 2004.

[16] Mola E, Negro P, Pinto AV. Evaluation of current approaches for the analysis and design of multi-storey torsionally unbalanced frames, Proc. of 13th World Conference on Earthquake Engineering, Vancouver, Paper No. 3304, 2004.

[17] Molina FJ, Buchet Ph, Magonette GE, Hubert O, Negro P. Bidirectional pseudo dynamic technique for testing a three-storey reinforced concrete building. Proceedings of the 13th World Conference on Earthquake Engineering, Vancouver, Paper No. 75, 2004.

[18] Negro P, Mola E, Molina FJ, Magonette GE. Full-scale PSD testing of a torsionally unbalanced three-storey non-seismic RC frame. Proceedings of the 13th World Conference on Earthquake Engineering, Vancouver, Paper No. 968, 2004.

[19] Fardis MN and Negro P. SPEAR - Seismic performance assessment and rehabilitation of existing buildings", Proceedings of the International Workshop on the SPEAR Project, Ispra, 2006.

[20] Jeong SH, Elnashai AS. Analytical assessment of an irregular RC frame for full-scale 3D pseudo-dynamic testing: part II- condition assessment and test deployment. Journal of Earthquake Engineering. 2005; 9(2): 265-284. https://doi.org/10.1080/13632460509350535

[21] Avsar Ö, Bayhan B and Yakut A. Effective flexural rigidities for ordinary reinforced concrete columns and beams. The Structural Design of Tall and Special Buildings. 2014; 23(6): 463-482. https://doi.org/10.1002/tal.1056 